\title{
KOMITMEN PEMERINTAH DAERAH DALAM PENGEMBANGAN EKOWISATA DI KABUPATEN SIDOARJO
}

\author{
Isnaini Rodiyah 1, Isna Fitria Agustina 2 \\ Program Studi Ilmu Administrasi Negara, FISIP Universitas Muhammadiyah Sidoarjo \\ Email: ${ }^{1}$ isnainirodiyah@ umsida.ac.id, ${ }^{2}$ isnaagustina@umsida.ac.id
}

\begin{abstract}
The purpose of this study is to describe the commitment of local governments in developing ecotourism. The research approach uses qualitative research with descriptive types. Data obtained from observation, interviews and documentation. Determination of informants using purposive sampling. Data were analyzed using the Miles \& Huberman interactive model. The results showed that Sidoarjo Regency Government (PKS) had a commitment to develop ecotourism in three dimensions. The first dimension of affective committees shows the strong will of PKS and consistently believes in the natural values of environmental issues by creating conservation lands and community development on the benefits of mangroves. Second, PKS normative commitment consistently acts in the form of planting 200,000 mangrove seedlings per year despite lack of maintenance in the Tlocor area which is claimed to be a mangrove tourist destination so that it becomes seedy and dirty resulting in quiet visitors. Third, continuance commitment PKS maintains the sustainability of ecotourism development by always coordinating between institutions in realizing ecotourism even though it has not been able to boost ecotourism development. Conclusion: PKS through related institutions tries to show commitment in ecotourism development but not yet optimal because of limited resources. For this reason, collaborative collaborative collaboration involves stakeholders, namely the Regional Government, the private sector (especially tourism developers) and the community in developing ecotourism areas using strategic management so that they can achieve results according to plan.
\end{abstract}

Keyword: Commitment, Local Government, Ecotourism.

\section{PENDAHULUAN}

Pariwisata menjadi salah satu motor penggerak perekonomian wilayah yang berpotensi mendatangkan pendapatan daerah. Berbagai daerah baik kabupaten maupun kota hingga provinsi bahkan negara berupaya giat mengembangkan potensinya sebagai aset wisata. Berbagai upaya dilakukan mengelola pariwisata didukung dengan perencanaan serta kebijakan matang dan terarah dalam bentuk misalnya ekonomi kreatif dan strategi integrated marketing communication sehingga memicu industri pariwisata terus tumbuh dan berkembang (Rochmaniah et al., 2015).

Sektor pariwisata di Jawa Timur memiliki prospek cerah dengan melihat jumlah kunjungan wisatawan mancanegara (wisman) yang masuk melalui Bandara Juanda di Sidoarjo dan kontribusi pariwisata terhadap PDRB.

Jumlah wismanke Jawa Timur tahun 2016 sebanyak 220.570 kunjungan atau naik sebesar 8,94 persen dibanding tahun sebelumnya yakni 200.851 kunjungan (BPS Jatim, 2016). Kontribusi sektor pariwisata di Jawa Timur terhadap Product Domestic 
Regional Bruto (PDRB) tahun 2016 sebesar Rp106,27 trilliun sedangkan 2015 sebesar Rp92,68 trilliun atau mengalami pertumbuhan sebesar 14,6\%. Sebagai perbandingan, kontribusi pariwisata terhadap PDRB Jatim 2015 sebesar 6,48\% sementara tahun 2016 sebesar 5,73\% (Kominfo, 2017).

Tingginya angka kunjungan wisman melalui Bandara Juanda menjadi peluang pasar wisata bagi PKS. Meski areal wilayahnya terbatas, Kabupaten Sidoarjo memiliki potensi yang dapat dikembangkan menjadi destinasi wisata lebih prospektif. Sidoarjo berada di urutan 6 dari 100 daerah tujuan investasi setelah DKI Jakarta, Surabaya, Bogor, Medan, dan Kota Kediri. Rerata pertumbuhan ekonomi Sidoarjo dalam kurun 5 tahun terakhir positif sebesar 5,17\%. Realisasi jumlah kunjungan wisata mengalami peningkatan sebesar 101\%. Sidoarjo memiliki Rencana Jangka Panjang Daerah (RPJPD) 2010-2015 dalam pengembangan potensi wisata berbasis konservasi di kawasan pesisir dan potensi wisata tersebar di 12 kecamatan (Rochmaniah et al, 2015).

Salah satu potensi pariwisata di Sidoarjo adalah wisata alam yang sangat menakjubkan yaitu kawasan mangrove. Melirik pariwisata sebagai entry point, proses peningkatan dan pemberdayaan potensi Sidoarjo menjadi penting dengan harapan angka kunjungan wisatawan terus meningkat setiap tahunnya.

Namun perlu diwaspadai kondisi kawasan hutan mangrove Kabupaten Sidoarjo yang membentang sepanjang 27 kilometer di 8 kecamatan kian mengkuatirkan karena abrasi air laut. Berdasarkan hasil analisis citra satelit Landsat ETM-7 perekaman tahun 2002 dan citra satelit ALOS-AVNIR perekaman tahun
2010 kawasan hutan mangrove seluas 1,236.42 hektar telah berkurang menjadi 1,203.35 hektar (Hidayah \& Wiyanto, 2013). Hal ini karena kurangnya kesadaran masyarakat dan lemahnya pengawasan aparat. Kondisi semakin memburuk dengan maraknya illegal logging dan penambahan area untuk lahan tambak oleh masyarakat di kawasan hutan mangrove (Hastareksa, 2015) berdampak ekologis mengancam kelestarian berbagai biota pesisir yang menjadikan hutan mangrove sebagai habitat serta secara fisik menghilangkan fungsi hutan mangrove mencegah abrasi pantai.

Sebagaimana yang terjadi pada beberapa wilayah di pantai utara yang telah mengalami abrasi pantai akibat rusaknya ekosistem mangrove antara lain di Kabupaten Lamongan, Gresik dan Surabaya (Arisandi, 2011) dalam (Hidayah \& Wiyanto, 2013), maka PKS harus berkomitmen menjaga kelestarian lingkungan. Kian maraknya penjarahan hutan mangrove secara illegal menjadi penyebab kawasan pantai terancam abrasi dan mengakibatkan populasi ikan tangkapan nelayan merosot (Widianto, 2010). Untuk itu, sesuai dengan UU 27/2007 dan peraturan bupati yang dituangkan dalam Perda 9/2011 tentang aturan tegas konservasi dan perlindungan kawasan hutan mangrove, PKS mengemban amanah yang tidak ringan dalam menjaga lingkungan.

Menyikapi keadaan tersebut, maka PKS mengambil langkah preventif agar ekosistem hutan mangrove yang ada di wilayah Sidoarjo tidak mengalami penurunan dan tetap terjaga dengan baik serta memiliki nilai guna bagi masyarakat dengan mengembangkannya menjadi kawasan ekowisata. 
Untuk itulah, penelitian ini dilakukan dengan maksud mengkaji lebih lanjut keseriusan dan komitmen pemerintah daerah dalam mengembangkan ekowisata di kabupaten Sidoarjo.

\section{METODE}

Penelitian komitmen pemerintah daerah dalam mengembangkan ekowisata hutan mangrove di Kabupaten Sidoarjo ini merupakan penelitian kualitatif dengan metode diskriptif sesuai permasalahan penelitian. Fokus penelitian pada komitmen dan berbagai upaya yang dilakukan pemerintah daerah dalam mengembangkan ekowisata hutan mangrove melalui lembagalembaga pemerintah.

Fokus pembahasan bertumpu pada konsep komitmen berdasarkan teori yang dikembangkan Allan \&Meyer (1990) terdiri atas 3 (tiga) jenis komitmen yaitu keyakinan PKS menerima nilai-nilai yang tertuang dalam program pengembangan ekowisata (affective commitment), kemauan kuat PKS menjalankan program kerja sesuai dengan tujuan pengembangan ekowisata (normative commitment), dan konsistensi yang ditunjukkan PKS melanjutkan program pengembangan ekowisata secara berkelanjutan (continuance commitment).

Data yang digunakan dalam penelitian ini merupakan data sekunder yang berasal dari dokumen-dokumen dari Dinas Pemuda, Olahraga, Budaya dan Pariwisata (Disporabudpar), Badan Lingkungan Hidup (BLH), Dinas Perikanan dan Kelautan (Diskanla), dokumen penelitian terdahulu mengenai ekowisata, serta data dari pemberiataan di media massa. Sementara data primer berasal dari wawancara dan observasi.
Teknik analisis data untuk menyimpulkan hasil penelitian menggunakan model interaktif dari Miles dan Huberman yang merupakan aktivitas analisis kualitatif secara interaktif dan terus-menerus sampai tuntas dimulai dari tahap pengumpulan data, reduksi data, verifikasi dan penyajian data hingga proses penarikan kesimpulan.

\section{HASIL DAN PEMBAHASAN}

Upaya dan komitmen PKS dalam pengembangan ekowisata hutan mangrove di Kabupaten Sidoarjo mengacu pada teori komitmen Allan \& Meyer (1990) yang terdiri atas 3 indikator komitmen yaitu: affective commitment, normative commitment, dan continuance commitment. Dalam penelitian ini, indikator komitmen dari Allan \& Meyer tersebut diterjemahkan menjadi ulasan keyakinan PKS untuk menerima nilai-nilai yang tertuang dalam program pengembangan ekowisata hutan mangrove (affective commitment), menguraikan kemauan kuat PKS dalam menjalankan program kerja yang sesuai dengan tujuan pengembangan ekowisata hutan mangrove (normative commitment), serta menjelaskan konsistensi yang ditunjukkan PKS untuk melanjutkan program pengembangan ekowisata hutan mangrove secara berkelanjutan (continuance commitment).

Keyakinan atas nilai-nilai yang tertuang pada pengembangan ekowisata berkaitan dengan nilai-nilai alami mengenai isu-isu konservasi lingkungan dan pemberdayaan masyarakat lokal, khususnya masyarakat pesisir. Nilai-nilai alami tersebut terwujud dalam bentuk berbagai upaya yang dilakukan untuk melestarikan dan mengembangkan hutan mangrove menjadi 
kawasan ekowisata yang menarik dan memberikan manfaat bagi masyarakat pesisir dengan prinsip pengembangan dari rakyat, oleh rakyat dan untuk rakyat.

Salah satu bentuk keyakinan atas nilainilai alami dalam pengembangan ekowisata telah dilakukan oleh Dinas Perikanan dan Kelautan (Diskanla) kabupaten Sidoarjo dengan pembuatan lahan konservasi mangrove seluas 250 Ha di Desa Gebang Kecamatan Sidoarjo.

Pembuatan lahan konservasi tersebut sebagai upaya untuk menjaga kelestarian mangrove dan mencegah semakin rusaknya kawasan hutan mangrove serta mensukseskan program pengembangan ekowisata hutan mangrove di Sidoarjo. Usaha ini sekaligus menindak lanjuti adanya UU No 7/2009 dan pembuatan sabuk hijau (green belt) yang memisahkan antara laut dan daratan sepanjang 300 meter sampai 400 meter (Abidin, 2012).

Lahan konservasi mangrove dapat dimanfaatkan masyarakat nelayan di sekitar lokasi dan diharapkan menjadi lebih prospektif sebagai sumber mata pencaharian alternatif selain mencari ikan di laut.

Selanjutnya, keyakinan atas nilai-nilai pemberdayaan masyarakat lokal juga telah dituangkan dalam program perencanaan pengembangan ekowisata. Melalui Dinas Perikanan dan Kelautan (Diskanla), PKS mengembangkan program dalam bentuk pembinaan kepada masyarakat mengenai manfaat mangrove. Dengan adanya pembinaan ini masyarakat dapat mengembangkan potensi yang ada pada hutan mangrove. Hasil dari program tersebut menghasilkan kemampuan anggota masyarakat dalam membuat manisan, sirup, teh dan berbagai hasil produk lainnya dengan bahan baku dari tanaman mangrove (Abidin, 2012). Realitas ini menunjukkan bahwa keyakinan PKS atas nilai-nilai alami dan sosial dalam pengembangan ekowisata sudah dijalankan melalui berbagai program berbasis pelestarian lingkungan dan pemberdayaan masyarakat.

Upaya pelestarian kawasan hutan mangrove melalui program penanaman bibit mangrove merupakan salah satu bentuk kemauan kuat yang ditunjukkan pemerintah dalam upaya pengembangan ekowisata hutan mangrove. Penanaman itu dilakukan di kawasan yang rusak akibat pembalakan ilegal. Pada tahun 2010, pemerintah juga telah menyebar sekitar 10 ribu bibit tanaman mangrove di wilayah Jabon. Sejumlah pesisir yang akan ditanami mangrove di antaranya daerah pesisir di Sedati, Waru dan Buduran (Widianto, 2010).

Kegiatan lainnya yang menunjukkan kemauan kuat PKS dalam mensukseskan pengembangan ekowisata adalah dengan melakukan pengawasan melalui kegiatan patroli yang melibatkan masyarakat pesisir. Kegiatan tersebut diprakarsai PKS melalui Badan Lingkungan Hidup (BLH) Kabupaten Sidoarjo dalam mensukseskan program pengembangan ekowisata hutan mangrove. Kegiatan patroli pesisir ini juga melibatkan masyarakat yang tergabung dalam Kelompok Masyarakat Pengawas (Pokmaswas) Bluru Kidul. Upaya patroli dengan masyarakat ini sebagai langkah antisipasi adanya penebangan liar yang dilakukan oleh sekelompok orang yang tidak bertanggung jawab. Hasil dari patroli tersebut menunjukkan bahwa sejauh ini tidak 
ditemukan adanya kerusakan di kawasan hutan mangrove.

Masyarakat sekitar juga dilibatkan dalam menjaga mangrove dari perusakan orang tak bertanggung jawab. Patroli pesisir yang dilakukan bersama tim terpadu juga untuk mengetahui sejauh mana perkembangan wilayah perairan di Sidoarjo. Kawasan hutan dengan tanaman mangrove yang tumbuh subur di Sidoarjo pernah dijarah pihak yang tak dikenal atau terjadi pembalakan liar. Dari kegiatan patroli diperoleh informasi dari salah seorang anggota Pokmaswas Bluru Kidul yang ikut dalam patroli pesisir bahwa saat ini pembalakan liar sudah jarang terlihat dibanding tahun-tahun sebelumnya. Bahkan dari hasil patroli ini dinilai sangat menguntungkan bagi masyarakat pesisir karena menurut mereka dahulu hampir tiap hari ada orang menebang mangrove tapi sekarang sudah tidak ada lagi (Miftakhudin, 2014). Melihat fakta atau realitas tersebut, maka dapat dikemukakan bahwa kemauan kuat PKS dalam pengembangan ekowisata sudah sesuai dengan harapan. Terdapat keterikatan dan kerjasama secara emosional dengan masyarakat pesisir untuk mensukseskan perencanaan yang telah ditetapkan.

PKS terbukti menunjukkan keyakinan serta kemauan kuat dan baik juga harus diikuti oleh konsistensi dalam kegiatan yang sesuai dengan pengembangan konsep ekowisata. Aktifitas penanaman bibit tanaman mangrove juga menjadi salah satu bentuk komitmen berkelanjutan PKS dalam mengembangkan program ekowisata. Setiap tahun, PKS dengan melibatkan warga masyarakat melakukan penanaman hingga
200.000 bibit tanaman mangrove di pesisir Sidoarjo. Penanaman tersebut bertujuan untuk mengendalikan abrasi dan menghindari banjir rob yang mengancam kawasan pesisir Sidoarjo (Widianto, 2011). Program pembinaan terus-menerus yang dilakukan oleh Diskanla kepada masyarakat pesisir dalam memahami manfaat tanaman mangrove akan menjadikan masyarakat lebih menyadari untuk senatiasa menjaga kelestarian mangrove. (Miftakhudin, 2014).

Konsistensi kebijakan lainnya yang ditunjukkan PKS adalah upaya menjadikan Pulau Sarinah atau Pulau Tanjung Lumpur menjadi salah satu destinasi ekowisata favorit. Pulau Sarinah merupakan pulau artifisial hasil sendimentasi lumpur Lapindo yang terletak di kampung Tlocor. Saat ini luas Pulau Sarinah mencapai 100 Ha dan kemungkinan bertambah karena luapan lumpur Lapindo hingga kini belum menunjukkan tanda-tanda akan berhenti (Fauziah, 2016). Pulau Sarinah yang dahulu gersang dan panas, kini mulai berubah sejak ditanami tanaman mangrove pada 2008. Kini Pulau Sarinah sudah menghijau dan resmi dibuka mulai tahun 2011.

Namun Pulau Sarinah sebagai destinasi wisata belum menarik perhatian. Hingga saat ini masih sepi dan belum banyak dikunjungi wisatawan. PKS berharap Pulau Sarinah menjadi destinasi ekowisata yang menarik dan mampu menandingi wisata bahari lain yang telah lebih dahulu dikenal masyarakat seperti Wisata Bahari Lamongan dan Taman Impian Jaya Ancol di Jakarta.

Reklamasi Pulau Sarinah yang diperbaharui Dinas Pemuda, Olahraga, Budaya dan Pariwisata Kabupaten Sidoarjo mengalami hambatan. Proses pengalihan 
fungsi lahan Pulau Sarinah dari BPLS kepada Kementerian Kelautan dan Perikanan baru terealisasi awal tahun 2017. Akibatnya, konsistensi PKS dalam mengembangkan ekowisata terhambat. Disadari bahwa keberadaan pulau ini awalnya sebagai lahan pembuangan lumpur dan bukan didesain untuk destinasi ekowisata. Oleh karena itu PKS tidak menyediakan sarana berupa media penunjang wisata (Sumedi, 2013). Dengan perubahan orientasi menjadi kawasan wisata, PKS diharapkan kian konsisten dalam mengembangkan Pulau Sarinah guna mendongkrak sektor pariwisata.

Upaya menjaga (maintenance) keberlanjutan pengembangan ekowisata yang telah dilakukan tentu lebih sulit dibandingkan dengan kegiatan yang telah dilakukan sebelumnya. Salah satu tantangan konsistensi pemerintah mengembangkan ekowisata ternyata berada di tangan pemerintah sendiri. Terdapat oknum tertentu yang memberi ijin kepada masyarakat menebang mangrove sekadar untuk membuka lahan tambak. Tercatat sekitar 600 petak lahan tambak milik warga yang berada di sepanjang pesisir Kecamatan Waru hingga Jabon sejauh 33 kilometer. Dengan melihat realitas tersebut, komitmen pemerintah mengembangkan ekowisata hutan mangrove tampak belum optimal. Dinas Perikanan dan Kelautan memang tidak dapat bertindak tegas melarang penebangan atau menjatuhkan sanksi kepada pelaku penebangan sekalipun tetap berusaha mengawasi ijin penebangan tersebut. Patokan pemberian ijin penebangan adalah hanya dapat dilakukan pada lahan yang berada 300 meter dari titik laut pasang tertinggi (Widianto, 2011).
Meskipun berpotensi, konsep ekowisata belum mampu menjadi ikon karena Kabupaten Sidoarjo lebih dikenal sebagai kawasan industri dan penyangga utama Kota Surabaya. Pengembangan ekowisata di Sidoarjo kurang terakomodasi dengan baik. Di sisi lain, dengan dukungan PAD mencapai Rp4 triliun, PKS seharusnya mampu mengembangkan beragam destinasi ekowisata yang menarik minat warga (Sukmana, 2016). Dinas Pariwisata sebagai penanggung jawab pengembangan ekowisata harus mampu bekerja sama dengan pihakpihak terkait. Selama ini masing-masing pihak terkesan berjalan sendiri tanpa perencanaan, koordinasi, dan kerjasama. Dinas Perikanan dan Kelautan yang telah mengembangkan lahan konservasi hutan mangrove sebaiknya diapresiasi dan didukung hingga menjadi kawasan ekowisata yang menarik.

Sementara itu, wisata kawasan Tlocor sebagai salah satu destinasi wisata bahari menakjubkan ternyata juga belum dikelola secara profesional. Meskipun sudah empat tahun dibuka, hingga saat ini sepi pengunjung dan nyaris memudar sebagai destinasi wisata.

Memudarnya Tlocor sebagai kawasan wisata disebabkan oleh beberapa hal: berada di daerah terpencil yaitu wilayah Sidoarjo pinggiran sehingga sulit diakses serta PKS kurang gencar berpromosi (Alfian,2016), kurangnya wahana atau fasilitas rekreasi lain yang mendukung (Humaira, 2016), dan tidak ada informasi jelas sebagai penunjuk arah ke tempat wisata. Kondisi lain yang juga tidak kalah penting untuk diperhatikan dalam pengembangan ekowisata di Tlocor ini adalah minimnya berbagai fasilitas umum meliputi areal parkir, tempat ibadah, area istirahat, dan tempat sampah. 
Sebagai leading sector pengembangan pariwisata, Dinas Pariwisata juga tidak dapat berbuat banyak karena terdapat wacana pengelolaan Tlocor dialihkan secara mandiri oleh masyarakat sekitar Jabon. Dengan memperhatikan wacana tersebut, Dinas Pariwisata seharusnya melakukan pendekatan pada tokoh masyarakat dalam menangani kondisi kawasan Tlocor yang tidak kondusif. Dengan pelibatan masyarakat, diharapkan dapat segera dilakukan pembenahan dan perbaikan sehingga layak untuk dijual kepada masyarakat sebagai wisatawan (Jawapos, 07/03/2016).

Belajar dari kasus Pulau Sarinah dan Tlocor, pengembangan ekowisata dengan penataan dan pengelolaan yang baik harus dikedepankan sehingga menjadi lebih menarik untuk dikunjungi dan menghindari terbentuknya kawasan kumuh.

Selanjutnya, dalam rangka pengembangan geopark di Pulau Sarinah telah dilakukan rapat koordinasi melibatkan instansi terkait. Berbagai pihak yang meliputi wakil dari Kementerian Kelautan dan Perikanan yaitu Ditjen PRL, Itjen, BROL, dan UPT BPSPL Denpasar; wakil PKS yaitu Bappeda, Dinas Kelautan dan Perikanan, Dinas Pariwisata, dan Dinas PU \& Tata Ruang; wakil Pemerintah Provinsi Jawa Timur yaitu Dinas Kelautan dan Perikanan Provinsi Jawa Timur, Gabungan Pengusaha Wisata Bahari (GAHAWISRI), dan juga melibatkan para akademisi dari Poltek Perikanan Sidoarjo. Rapat koordinasi dimaksudkan menyusun rencana dan pengembangan konsep geopark Pulau Sarinah agar segera dapat dilaksanakan serta terkelola dengan baik (Parwati, 2017).
Berdasarkan uraian yang telah disajikan, dapat dikatakan bahwa komitmen PKS melalui berbagai instansi terkait tampak belum dapat berjalan dengan baik terutama konsistensi dalam rencana dan kegiatan yang mendukung pengembangan ekowisata. Selain itu, PKS juga dianggap kurang serius dan kurang perhatian dalam pengembangan pariwisata. Koordinasi di antara SOTK PKS bersama para pemangku kepentingan (stakeholders) dalam mengoptimalkan potensi pariwisata juga kurang optimal. Pengembangan sarana penunjang wisata berupa moda transportasi ke objek daerah tujuan wisata (ODTW) juga belum dilakukan. Upaya pengembangan ekowisata hutan mangrove juga belum mampu memberikan dampak bagi peningkatan kesejahteraan masyarakat sekitar. Hal ini menunjukkan komitmen PKS untuk mengimplementasikan sapta pesona masih belum optimal.

Dengan demikian, konsistensi PKS dalam pengembangan ekowisata hutan mangrove harus kian dioptimalkan. Tanpa konsisteni, pengembangan destinasi ekowisata yang telah ada (Pulau Sarinah dan Tlocor) tidak akan dapat menjadi destinasi wisata menarik bagi wisatawan. Pembaharuan konsep wisata geopark juga harus disertai perencanaan matang. Rencana pembangunan kereta gantung untuk mendukung pembaruan Pulau Sarinah harus mengedepankan komunikasi dengan masyarakat agar efektif. Informasi penting dari masyarakat harus menjadi dasar bagi pengembangan geopark sehingga mendapat dukungan sepenuhnya. Jika ekowisata dikemas dengan sedemikian rupa, bisa jadi geopark akhirnya menjadi ikon wisata baru 
Sidoarjo baik bagi wisatawan dalam maupun luar negeri (Rouf, 2016).

Badan Promosi Pariwisata Daerah (BPPD) Sidoarjo dalam mempromosikan potensi wisata harus mengedepankan "performance tourism to Sidoarjo" serta melibatkan swasta dan memberdayakan masyarakat pesisir di sekitar lokasi ekowisata. Keterlibatan dan dukungan semua pihak diyakini mampu memperkuat BPPD Sidoarjo dalam mengembangkan industri pariwisata secara efektif (Metronews, 2017).

\section{KESIMPULAN DAN SARAN}

Kesimpulan yang diperoleh dari penelitian ini menunjukkan bahwa komitmen PKS mengembangkan kawasan ekowisata belum semuanya berjalan dengan baik. Keyakinan dan kemauan kuat PKS yang ditunjukkan Dinas Perikanan dan Kelautan (Diskanla) dan Badan Lingkungan Hidup (BLH) melalui pembuatan lahan konservasi, penanaman kembali hutan mangrove, dan pelaksanaan patrol pesisir melalui Pokmaswas sudah berjalan dengan baik. Di sisi lain, konsistensi Diskanla serta Dinas Pemuda, Olahraga, Budaya dan Pariwisata (Disporabudpar) dalam pengembangan ekowisata kurang optimal. Keluarnya ijin penebangan hutan mangrove oleh PKS serta kurang optimalnya promosi kawasan ekowisata menyebabkan Pulau Sarinah dan kawasan Tlocor sepi pengunjung. Konsistensi pengembangan ekowisata pada gilirannya mengalami hambatan.

Untuk memberi nilai tambah kawasan ekowisata, pembaharuan konsep ekowisata dalam bentuk geopark di Pulau Sarinah hendaknya segera direalisasikan secara tuntas. Pengembangan

dilakukan

dengan mengedepankan perencanaan matang berdasarkan evaluasi pengembangan ekowisata yang telah dilakukan sebelumnya. Perwujudan geopark dapat dikatakan sebagai langkah nyata pembaharuan ekowisata. PKS harus mampu melibatkan semua pihak baik internal maupun eksternal dalam bentuk kerjasama yang sinergis dan kolaboratif untuk mengembangkan ekowisata sehingga sektor pariwisata memberi kontribusi nyata bagi pembangunan Kabupaten Sidoarjo serta peningkatan kesejahteraan masyarakat.

\section{DAFTAR PUSTAKA}

Abidin. (2012). Sidoarjo Siapkan Lahan Konversi Mangrove. Diakses Juli 29, 2017, dari http:/ / kabarsidoarjo.com/2012/05/0 6/ sidoarjo-siapkan-lahan-konversimangrove/

Allan, N. J. \& Meyer, J. P. (1990). Measurement of Antecendents of Affective, Continuance and Normative Commitment to Organizational. Journal of Occupational Psychology, 63:1-8.

Alfian, R. (2016). Destinasi Wisata Hutan Mangrove Tlocor Sidoarjo Cocok untuk Memancing. Diakses Juli 28, 2017, dari https://www.bangsaonline.com/beri ta/26781/destinasi-wisata-hutanmangrove-tlocor-sidoarjo-cocokuntuk-memancing.

Almira, A. (2017). Hutan Mangrove Bisa Diperdayakan Jadi Obyek Wisata. Diakses 13 Agustus 2017 dari https://www.agata.id/hutanmangrove-bisa-diberdayakan-jadiobjek-wisata-16641/ 
BPS Jatim. (2016). Statistik Pariwisata Provinsi Jawa Timur 2016. Surabaya: BPS Provinsi Jawa Timur.

Fauziah, N. (2016). Pulau Sarinah, Tempat Wisata Yang Terkepung Lumpur Sidoarjo. Diakses September 28, 2017 dari

https://sportourism.id/tourism/pula u-sarinah-tempat-wisata-yangterkepungan-lumpur-sidoarjo.

Hastareksa. (2015). Hutan Mangrove Sidoarjo Makin Kritis. Diakses Juli 28, 2017, dari

http:/ / surabayaonline.co/2015/11/2

0/hutan-mangrove-sidoarjo-makinkritis/

Hidayah, Z. \& Wiyanto, D. W. (2013). Analisa

Temporal Perubahan Luas Hutan Mangrove di Kabupaten Sidoarjo Dengan Memanfaatkan Data Citra Satelit. Jurnal Bumi Lestari, Volume 13 (2): 318 - 333.

Humaira, D. A. (2016). Wisata Hutan Bakau di Sidoarjo Kurang Berkembang. Diakses Juli 28, 2017, dari http:/ / www.kompasiana.com/denis haltha/wisata-hutan-bakau-disidoarjo-kurangberkembang_56bd963bc222bd9a068ca 670

Jawapos. (2016). Wisata Bahari Tlocor Tidak Terawat. Diakses 25 Agustus 2017 dari https://www.pressreader.com/indon esia/jawa-

pos/20160307/282621736808703.

Kominfo.(2017). Pemprov Target Transaksi MTF 2017 Capai Rp 56 Miliar. Diakses Juli 28, 2017, dari http://kominfo.jatimprov.go.id/read
/ umum/pemprov-target-transaksimtf-2017-capai-rp-56-miliar

Metronews. (2017). Diakses Juli 29, 2017, dari https:/ / babe.news/read/13603751/b ppd-mulai-promosikan-potensiwisata-pulau-lumpur-sidoarjo/

Miftakhudin, A. (2014). Jaga Kelestarian, Dinas Kelautan Sidoarjo Sisir Hutan Mangrove. Diakses Juli 28, 2017 http:/ / surabaya.tribunnews.com/201 4/04/21/jaga-kelestarian-dinaskelautan-sidoarjo-sisir-hutanmangrove

Parwati, Putu. (2017). Rapat Koordinasi Pengembangan Pulau Lusi Sidoarjo. Diakses tanggal 24 Agustus 2017 dari http://www.bpol.litbang.kkp.go.id/2 5-berita-terkini/ 234-rapat-koordinasipengembangan-pulau-lusi-sidoarjo.

Rochmaniah, A.(2015). Model Ekowisata Bahari Berbasis Pemberdayaan Masyarakat Untuk Peningkatan Ekonomi Lokal (PEL) Di Kawasan Strategis Pesisir Kabupaten Sidoarjo. Laporan Akhir Penelitian Hibah Bersaing, Universitas Muhammadiyah Sidoarjo.

Rouf, A. (2016). Lumpur Lapindo Ikon Baru Sidoarjo. Diakses Juli 28, 2017 dari http://koransindo.com/page/news/2016-10$07 / 6 / 126$

Sukmana, H. (2016). Menggagas Pengembangan Potensi Wisata di Kabupaten Sidoarjo. Diakses 24 Agustus $\quad 2017$ dari http:/ / www.visioner.id/opini/10277 /menggagas-pengembangan-potensiwisata-di-kabupaten-sidoarjo.html 
Sumedi, D. (2013). Wisata Pulau Lumpur Lapindo Sepi Peminat. Diakses September 28, 2017, dari https://nasional.tempo.co/read/5080 32/wisata-pulau-lumpur-lapindosepi-peminat

Widianto, E. (2010). Penjarahan Hutan Mangrove Sidoarjo Terus Meningkat. Diakses Juli 28, 2017, dari https://m.tempo.co/read/news/2010 /06/16/180255893/penjarahanhutan-mangrove-sidoarjo-terusmeningkat.

Widianto, E. (2011). Kerusakan Hutan Mangrove Timbulkan Banjir Rob. Diakses Juli 28, 2017 dari https://m.tempo.co/read/news/2011 /03/13/180319684/kerusakan-hutanmangrove-timbulkan-banjir-rob. 